\title{
Pattern-recognition, intersubjectivity, and dialogic meaning-making in education
}

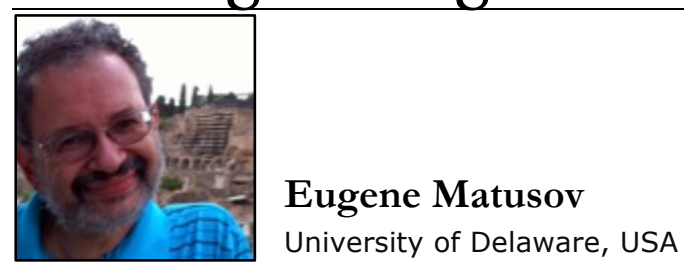

\begin{abstract}
From a conventional monological view, meaning-making is located in a particular statement. In conventional schools, students are positioned to be enactors of ready-made knowledge and skills on teacher's demand based on their patternrecognition and production, rather than to be authors of their own education, learning, knowledge, and meaning. Pattern recognition involves the emergence of active production of diverse potential patterns that may or may not approximate well the targeted pattern ("sprouting"). The sprouting can be guided ("supervised") by an expert or unguided, mediated or unmediated. These diverse potential patterns are sequentially evaluated about how likely each of them can be close to the targeted pattern. In each evaluation, the probabilistic confidence of some patterns grows while some other patterns decrease. In contrast, according to Bakhtin, meaning-making is defined as the relationship between a genuine, interested, information-seeking, question and serious response to it. From the Bakhtinian dialogic perspective, a statement does not have any meaning until it is viewed as a reply to some question in an internally persuasive discourse. A student's meaning-making process starts with a genuine, interested, information-seeking, question raised by the student. At least, when a student cannot yet formulate this genuine question, they have to be pregnant with such a question, experiencing a certain puzzlement, uneasiness, curiosity, tension, and so on. Another aspect of dialogic meaning-making is interaddressivity. A student is interested in other people: 1) in what other people may think and how they feel about it; however these people define this it, and 2) in other people as such - in what they are doing, feeling, relating, and thinking about; in the relationship with these people; in the potential that these people may realize and offer; and so on.
\end{abstract}

Eugene Matusov is a Professor of Education at the University of Delaware. He studied developmental psychology with Soviet researchers working in the Vygotskian paradigm and worked as a schoolteacher before immigrating to the United States. He uses sociocultural and Bakhtinian dialogic approaches to education. His recent books are: Matusov, E. (2017). Nikolai N. Konstantinov's authorial math pedagogy for people with wings, Matusov, E. \& Brobst, J. (2013). Radical experiment in dialogic pedagogy in higher education and its Centauric failure: Chronotopic analysis, and Matusov, E. (2009). Journey into dialogic pedagogy.

$\cos \cos 80$

My central thesis in this essay is that learning in conventional and many progressive schools mainly involves individual or social pattern-recognition and pattern-production, patched and facilitated with 


\section{Pattern-recognition, intersubjectivity, and dialogic meaning-making in education}

Eugene Matusov

occasional dialogic meaning-making ${ }^{1}$ process (as it often happens in constructivist progressive teaching). Let me provide an example. I frequently asked my undergraduate college students, future teachers, what they learned deeply in school and are proud of learning. Often, many of my students pick up adding fractions with different denominators, like $1 / 2+1 / 3^{2}$. They usually feel very proud to demonstrate the math procedure of multiplying both the nominator and denominator of $1 / 2$ by 3 and both the nominator and denominator of $1 / 3$ by 2 to make the common denominator 6 and then add the new, transformed, fractions 3/6 and 2/6 together to get $5 / 6$. So far, so good. But then, I ask them why we cannot do simpler addition by adding the two nominators 1 and 1 together and by adding the two denominators 2 and 3 together to get 2/5. My students usually say that it would be the wrong addition of the fraction. I ask them what makes the first addition of fractions that they did right and while the second addition that I did wrong.

This is where the most interesting thing starts because my students rarely can answer this question. Many of them get angry at me for "tricking them." They say, "It's forbidden." I ask, "By whom?" They say, "You will fail a test." I suggest, "Why don't we change the tests." And so on. Finally, I ask my students how and why humans, humankind, came to this strange rule of adding fractions. They do not know. In my view, the main problem is not that my students do not know many things about the addition of fractions, but the problem is that many of them have never been set on a journey of understanding about fractions. Rather, it seems that many of them were conditioned to produce a certain pattern of actions, approved by the school authority (and beyond).

A similar question in science often brings an answer that the Earth is round - a scientific fact that many of my students, future teachers, claimed that they knew well. When I ask them how they know that it is true, my students often say that they learned it from their science textbooks. When I ask how the textbook, the scientists, the humankind know for sure that it is true. At best, my students could tell me that humans can see the Earth from space. I often counter-argued that humans knew that the Earth was round long before they could go to space - but how did they know? For the vast majority of my students, these questions were new.

In my view, the issue here is not necessarily that most of my college students have experienced a particularly poor instruction and particularly bad teachers. The problem seems to be that apparently, something is very rotten with conventional schools themselves. Although a conventional teacher can teach my students to answer my questions correctly, still the problem will reemerge when new, "tricky," questions, unexpected by the students, arrive. In conventional ${ }^{3}$ schools, students are positioned to be enactors of ready-made knowledge and skills on their teachers' demand, rather than to be authors of their own education, learning, and knowledge. Let me illustrate this point by considering experiments by the famous Soviet cultural-historical psychologists Luria and Vygotsky (Luria, 1976; Vygotsky \& Luria, 1993) that were then critically re-thought by the American psychologist Scribner (1977).

The issue of whether the meaning-making process is rooted in pattern-recognition or in dialogue is very important because it defines the nature of education: either mostly monological or mostly dialogical.

\footnotetext{
${ }^{1}$ In this essay, I use the terms "meaning-making" and "sensemaking" interchangeably and synonymously. I should probably have used the term "sensemaking" to be exact, but I follow the conventional term "meaning-making," which is often used in place of "sensemaking." For the purpose of this essay, I am not going to distinguish the terms "meaning" and "sense."

2 The other common learnings are: 1) the fact that the Earth is around, 2) the explanation of the seasons, and 3) the explanation of the Moon's phases. Like in the case of the adding fractions with different denominators, not only these learnings are usually conventional but also are full of misconceptions (especially for \#2 and \#3).

${ }^{3}$ I use the term "conventional" here in two different ways. The first is as a synonym of "mainstream". The second is schools, which pedagogy is based on socializing students in conventionality (see my notion of "conventional knowledge" in contrast to "conceptual knowledge," Matusov, 2009).
} 


\section{Pattern-recognition, intersubjectivity, and dialogic meaning-making in education}

Eugene Matusov

\section{Unpacking schoolish pattern-recognition}

In the early 1930s, Aleksandr Luria went to Soviet Asia to conduct psychological experiments with the illiterate and unschooled local population, comparing them to their literate and schooled neighbors. Vygotsky and Luria (1993) expected to find evidence of qualitative differences in the participants' psychological functions such as cognition because they believed that literacy and school provide people with new psychological mediational tools, which transform their cognition and other psychological functions. The results of the experiments seemed to confirm the Vygotsky-Luria hypothesis about cognitive mediation by cultural tools. They found that, in contrast to literate schooled local activists, illiterate, unschooled adults could not solve logical syllogisms - the concept invented by Aristotle:

[Syllogism] In the Far North, where there is snow, all bears are white. Novaya Zemlya is in the Far North and there is always snow there. What color are the bears there?

1. Illiterate Unschooled Peasant: ...We always speak only of what we see; we don't talk about what we haven't seen.

2. Experimenter: ...But what do my words imply? [The syllogism is repeated.]

3. P: Well, it's like this: our tsar isn't like yours, and yours isn't like ours. Your words can be answered only by someone who was there, and if a person wasn't there, he can't say anything on the basis of your words.

4. E: ...But on the basis of my words - in the North, where there is always snow: the bears are white, can you gather what kind of bears there are in Novaya Zemlya?

5. P: If a man was sixty or eighty and had seen a white bear and had told about it, he could be believed, but I've never seen one and hence I can't say. That's my last word. Those who saw can tell, and those who didn't see can't say anything! (At this point a young [schooled] Uzbek [Communist activist] volunteered, "From your words it means that bears there are white.")

6. E: Well, which of you is right?

7. P: What the cock knows how to do, he does. What I know, I say, and nothing beyond that! (Luria, 1976, pp. 108-109).

Vygotsky and Luria argued that the illiterate, unschooled peasant could not abstract from his everyday experiences and did not possess the cognitive abilities of hypothetical thinking. However, later, American psychologist Sylvia Scribner (1977) re-analyzed the case and pointed out that the illiterate, unschooled Uzbek peasant demonstrated his hypothetical thinking perfectly well when he argued, "If a man was sixty or eighty and had seen a white bear and had told about it, he could be believed, but l've never seen one, and hence I can't say" (see turn 5 above). The peasant used abstract thinking to refuse to cooperate - to play the formal logic game - with the unknown adult researchers who come as some kind of authority to impose their test on him. Scribner also showed that the illiterate Uzbek peasant demonstrated abstract and generalizable thinking as well, although different than what Vygotsky and Luria expected. Thus, the reason, for which the illiterate, unschooled peasant rejected the syllogism premise, "In the Far North, where there is snow, all bears are white," was not rooted in "imprisonment by everyday experiences" and a lack of abstract and hypothetical thinking, as Vygotsky and Luria thought, but in something else.

Scribner attracted our attention to the fact that the syllogism premise, as probably all syllogism premises, does not make much sense outside of this syllogism game. Indeed, what does it mean, "In the Far North, where there is snow, all bears are white"? Who said that? Are those people trustworthy? What does it mean "all"? Is it about (somebody else's) past or about everybody's future? What if somebody brings a black bear to the Far North, would the Far North stop being the Far North or would snow disappear? What 


\section{Pattern-recognition, intersubjectivity, and dialogic meaning-making in education}

Eugene Matusov

if non-white bears exist or existed in the Far North, but we do not know that yet? And so on. The premise is arbitrary (although often not random).

Scribner turned the table around: instead of considering the strange peculiarity of illiterate, unschooled society, we should focus on the strange peculiarity of schooled societies. In a clever research, Scribner and her colleague Cole (1981) disentangled literacy and schooling and came to a conclusion that it is schooling and not literacy per se that is responsible for the phenomenon observed by Luria. Interestingly enough, Aristotle abstracted the formal logic and the notion of syllogism from the teaching practice of sophists - Ancient Greek teachers of wealthy Athenian youth. Sophists tutored young aristocrats for pay how to win arguments in democratic debates by focusing on the rhetoric and form of the arguments rather than on their content. The content-free logic (and logical traps) allowed sophists to teach young aristocrats from different political parties, regardless of their political ideology, in contrast to teachers who focused on the content of the political arguments and, thus, who had a more limited pool of their students. Teaching the formal logic was economically more profitable and politically safer than teaching the content logic developed by Socrates in democratic Athens. The issue is why this strange practice spread beyond democratic Ancient Athens.

It seems that what people learn in school is not so much new cognitive mediational tools, as Vygotsky and Luria argued, but rather a peculiar ability to seamlessly abstract or decontextualize from their own meaningfulness, rooted in meaning-making critical questions, and uncritically accept any arbitrary premise imposed by the authority. In my upcoming book, I try to address the important issue of why conventional school does that and what role it serves in our society (and what "our society" means) (Matusov, 2020, in press). In this essay, I will continue exploring the peculiarity of learning in conventional schools.

I argue that this type of learning, alienated from the student's own meaning-making process, is mainly rooted in the pattern-recognition and pattern-production processes, guided by the authority's approval or disapproval. Such patterns may involve cognitive, such as in syllogistic problem solving, discursive, as in talking about invisible electrons, action patterns, as when adding fractions with different denominators, perceptional patterns, as when seeing 4 in the 2+2 statement, communicational patterns, e.g., not talking until allowed by the teacher, power patterns, such as unconditionally accepting any question or any assignment demanded by the teacher, and so on. Students have to recognize patterns desirable by the authority and successfully produce them as judged by the authority. Of course, pattern-recognition and pattern-production occur outside of conventional school. Furthermore, one can legitimately argue that pattern-recognition and pattern-production are ubiquitous and omnipresent. Yes, but pattern-recognition and pattern-production in conventional school is different from the one occurring elsewhere by at least two mutually related accounts.

First, in conventional schools, patterns to be recognized and produced are arbitrary ${ }^{4}$, most often lie outside of the immediate experiences of the learners and are not rooted in the everyday practices of the society outside of the schooling-testing industry. In extreme cases, the teacher can teach whatever nonsense the teacher wants to teach regardless of its truthfulness or usefulness - conventional schooling does not have a feedback loop with targeted practices that schooling is supposed to serve. In other words, conventional school is viewed as a near-perfect self-contained tool to shape students' subjectivity in whatever way a teacher or the entire society wants or needs. That is why conventional schools in politically, socially, and economically different societies - whether totalitarian, authoritarian, or democratic - look pretty

${ }^{4}$ Of course, this arbitrariness is relative to a student. Conventional schools' curriculum is shaped by the powerful ideological hegemonies of the society.

Dialogic Pedagogy: An International Online Journal | https://dpj.pitt.edu

DOI: 10.5195/dpj.2020.314 | Vol. 8 (2020) 
much the same. The content of teaching (i.e., the curriculum) can be different at times - e.g., in the totalitarian Communist USSR, it was taught that mostly the Red Army won WWII, while in the democratic Capitalist US it was taught that mostly the US Army won WWII. However, the organization of educational practices is often very similar: quizzes, exams, lecturing, sitting silent, unconditional assignments, the unquestionable teacher authority, expulsions, and so on. In contrast, in many other practices and contexts, patterns to be recognized and produced are often pragmatic - not arbitrary - but embedded and subordinated to the practices and contexts themselves. There, what guides pattern-recognition and patternproduction is success or failure in the pragmatics of the practice or context, mediated by the person's own sense-making, rather than the arbitrary authority of the teacher or the society at large.

Second, in conventional schools, the (dialogic) meaning-making process is subordinated to the pattern-recognition and production rather than the other way around. In conventional schools, a student's own sense-making is often overruled by the teacher's pattern of thinking, action, perception, and so on. It usually does not matter what makes sense for the student; what matters is what makes a good answer (for the teacher), good performance, good grade, and good mark produced by the teacher, testing agency, or society at large. The role of the student's meaning-making is diligently to serve the latter. For example, a first-grader may sense that for some objects $2+2$ is not always 4 (e.g., two friends and two friends does not always make four friends) (Matusov, 2009, Chapter 4; 2020, in press, Chapter 9) but this sensemaking is in contradiction with the school unconditional pattern that 2+2 is ALWAYS 4 when one counts the same things and one should not challenge it. At best, to be successful in a conventional school, a student may develop double-consciousness (Du Bois, 1961) to learn that in school 2+2 is always four, but outside of school, it may not be so. At worst, the student may be brainwashed into accepting the school pattern as always true. In-between, the student may give up on school success by rejecting the school pattern while remaining faithful to his/her own private sensemaking. In any case, the student's private authorial sensemaking remains undeveloped by the critical public dialogue that is genuine education.

One the other hand, the student's authorial sensemaking can become a legitimate and public aide (facilitator) when it is subordinated to school pattern-recognition and pattern-production. If according to school pattern, 2+2 is always 4, then two hundred(s) plus two hundred(s) is four hundred(s) regardless of how perceptually confusing it may look to a child (Matusov, 2009, Chapter 4; 2020, in press, Chapter 9). A student is allowed to reason and make sense if and only if it leads to the authoritative school pattern, and the student's reasoning is approved by the school authority. A student's personal sense-making can also patch school patterns when they become obviously out of touch with reality by rationalizing the questionable school arbitrary patterns. For example, when I challenged my student who, based on a school science textbook, insisted that the Moon passes monthly the space between the Earth and the Sun, he agreed with me that according to this model, a solar eclipse would occur every month. He added that a solar eclipse happens every lunar month, but it just happens in different parts of the Earth and thus remains unregistered by most people. Conventional schools are often criticized that learning is decontextualized for their students (Forman, Minick, \& Stone, 1993; Lave, 1988, 1992), which is, of course, true. But even more so, conventional school learning is de-ontologized ${ }^{5}$, de-personalized, voiceless, and stripped of any student activism and authorial agency by often colonizing the student, making them agentive (Milgram, 1974).

\section{Example of schoolish pattern-recognition and production in a science lesson}

In his book "Talking science" on science education in conventional school, researcher of science education Jay Lemke (1990) argues that this process of pattern-recognition and pattern-production occurs

\footnotetext{
${ }^{5}$ Of course, one can say that any learning is ontological in a sense that it is a part of the life of a student. But in conventional schools, it is not ontological with the regard of its content. Students often learn to please the teachers (and parents) rather than because they are genuinely interested in the academic content.
} 


\section{Pattern-recognition, intersubjectivity, and dialogic meaning-making in education}

Eugene Matusov

through and in a special pedagogical discourse. In conventional schools, students are guided by the teacher to learn to recognize and produce certain ready-made themes about science (or another academic subject) approved by the authority of the teacher (and tests, exams, and the broader society). Lemke argues that this learning goes much beyond rote memorization of vocabulary, procedures, or definitions but it is rather the recognition and production of holistic thematic patterns that involve certain beliefs, perceptions, actions, semantics, social relations, contexts, and power. Students not only learn to hear and talk about the pattern but also to see the world through and act by this discursive pattern.

In his book "Talking science" on science education in conventional school, researcher of science education Jay Lemke (1990) argues that this process of pattern-recognition and patternproduction occurs through and in a special pedagogical discourse. In conventional schools, students are guided by the teacher to learn to recognize and produce certain ready-made themes about science (or another academic subject) approved by the authority of the teacher (and tests, exams, and the broader society). Lemke argues that this learning goes much beyond rote memorization of vocabulary, procedures, or definitions but it is rather the recognition and production of holistic thematic patterns that involve certain beliefs, perceptions, actions, semantics, social relations, contexts, and power. Students not only learn to hear and talk about the pattern but also to see the world through and act by this discursive pattern.

The science in the dialogue is not just a matter of vocabulary. Classroom language is not just a list of technical terms, or even just a recital of definitions. It is the use of those terms in relation to one another, across a wide variety of contexts. Students have to learn how to combine the meanings of different terms according to the accepted ways of talking science. They have to talk and write and reason in phrases, clauses, sentences, and paragraphs of scientific language.

$\cdots$

The pattern of connections among the meanings of words in a particular field of science I will call their thematic pattern. It is a pattern of semantic relationships that describes the thematic content, the science content, of a particular topic area. It is like a network of relationships among the scientific concepts in a field, but described semantically, in terms of how language is used in that field. There is science in the dialogue exactly to the extent that the semantic relationships and the thematic pattern built up by the dialogue reproduce the thematic pattern of language use in some field of science (Lemke, 1990, pp. 12-13).

Lemke illustrates this pedagogical discursive process of the male teacher's guiding his high school students into this pattern-recognition and pattern-production process by the following excerpt from a science lesson discourse about the quantum model of the atom:

Before his first question, the teacher describes the diagram he has on the board (see Figure 1.1). He points to the central area of the diagram and identifies it as "the $1 \mathrm{~s}$ orbital." He points out that the diagram does not show that it really looks like a sphere, that is, three- rather than two dimensional as it appears on the board. Only then does he ask a question which refers directly to the diagram, and not to the whole of it, but specifically to the part of it he has just described. He has prepared a context for his question first. Without the preparatory statements, the question would have been ambiguous or confusing for the class. (p. 6)

Dialogic Pedagogy: An International Online Journal | https://dpj.pitt.edu DOI: $10.5195 /$ dpj.2020.314 | Vol. 8 (2020) 


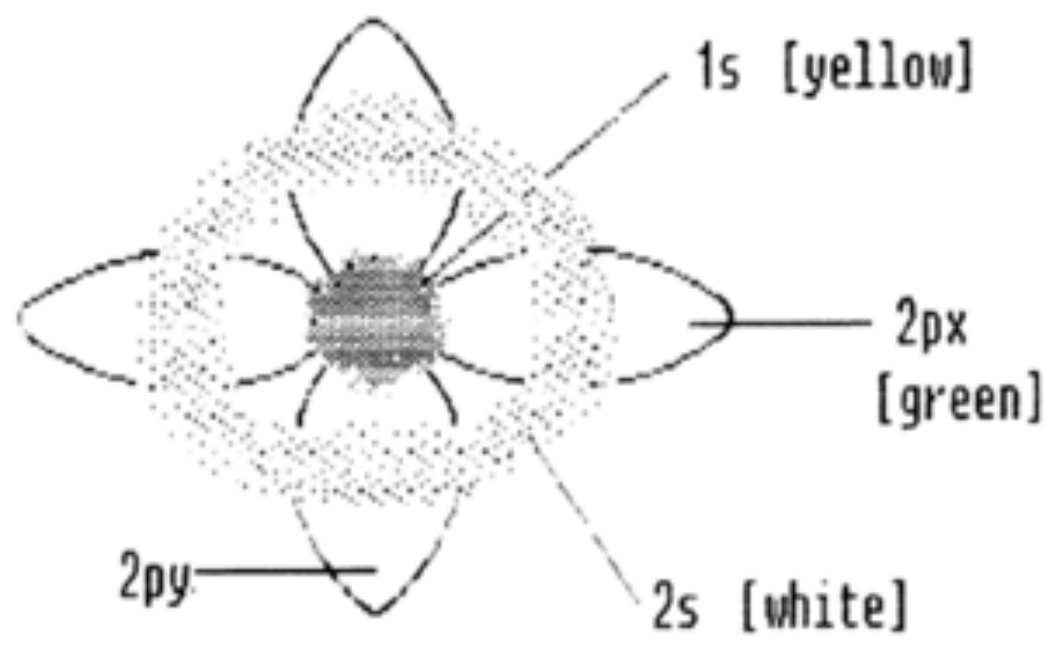

Figure 1: Atomic Orbital Diagram (Lemke, 1990, p. 6)

Teacher: This is a representation of the one S . . orbital. S'pozed to be, of course, three dimensional... What two elements could be represented by such a diagram? . . . Jennifer?

Jennifer: Hydrogen and helium?

Teacher: Hydrogen and helium. Hydrogen would have one electron... somewhere in there, and helium would have ...?

Student: Two electrons.

Teacher: Two... This is... one $\mathrm{S}$, and... the white would be...? Mark?

Mark: Two S.

Teacher: Two S. And the green would be...? Uhh...

Janice: Two P. Two P.

Teacher: Janice.

Janice: Two P.

Teacher: Two P. Yeah, the green would be $2 \mathrm{P} x$ and $2 \mathrm{P}$ y. (p. 5)

In this excerpt, the students learn a discursive pattern regarding the quantum model of the atom by learning the correct way of talking about it through making the correct clarifications, correct inferences, and correctly answering the teacher's questions. The teacher's quizzing questions are aimed at testing the students' existing understanding of the model but also at expanding this knowledge, which is nothing more but an intricate thematic pattern, as Lemke argues. Students may doubt or guess in their reply to the teacher's quizzing questions as Jennifer did ("Hydrogen and helium?). Their answer can be not elaborated or incomplete, as in the case of Janice (it was not just 2P but 2Px and 2Py). It can be entirely correct, like in the case of Mark. Of course, it can be partially or even totally wrong, which was not presented in the excerpt. Lemke argues that the students learn not "doing science," but "talking science" - production of correct discursive patterns. This recognition and production of correct discursive patterns arguably is similar to how Siri or Alexa produce and recognize "speech" on smart devices. 


\section{The mechanism of schoolish pattern-recognition}

\section{Student semantic sprouting}

Pattern-recognition - the term emerged in German gestalt psychology (Koffka, 1935; Köhler, 1929) and was then actively used in computer science (Bishop, 2006) - involves the emergence or active production of diverse potential patterns that may or may not approximate the targeted phenomenon well (what I call "sprouting"). This sprouting can be guided ("supervised") by an expert or unguided - near randomly produced (Sutton \& Barto, 1998), mediated or unmediated. These diverse potential patterns are sequentially evaluated on how likely each of them can be close to the targeted pattern. In each evaluation, the probabilistic confidence of some patterns grows while that of some other patterns decreases. Strictly speaking, the winner pattern always remains probabilistic and never $100 \%$ certain as a new evaluation may change its probability to be the correct pattern. Evaluation of potential patterns involves an action, in which the potential patterns are tested against the targeted phenomenon. Often, the pattern-recognition includes many targeted patterns at once and is organized in a complex. For example, OCR (optical character recognition) that involves a program recognizing a scanned photo image of a text may include letter-patternrecognition, word-pattern-recognition, sentence-pattern, context-pattern-recognition, and so on (Bishop, 2006; Sutton \& Barto, 1998). One can argue that the modern computer-based pattern-recognition can be called "probabilistic cognitive behaviorism" as it is indifferent to goals, subjectivities, desires, rules, strategies, and so on and essentially based on "rewards" and "punishments" that change probabilistic weights for possible outcomes of a complex system.

In conventional schools, students are active in sprouting out new semantic connections-inferences in the classroom subject-thematic discourse, as the students did in the excerpt in their response to the teacher's lecture and questioning. Some of this semantic sprouting is done by the students privately while some publicly. Some students probably sprout the semantic connections when they were listening to the teacher's lecture and watching the visual model of the atom (see Error! Reference source not found. above). The teacher's mini-lecture promotes and provokes the students' semantic sprouting. I agree with Lemke, "Without the preparatory statements, the [teacher's initial] question would have been ambiguous or confusing for the class" (p. 6). We do not know how present, active, and deliberate this private process of semantic sprouting was for each and every student in the class. That is why, probably, a conventional teacher often seeks students' public sprouting in public discourse. By asking challenging quizzing questions, the teacher promotes possible public sprouting through the students' answers and silently in their heads.

It is reasonable to assume that when Jennifer, Mark, Janice, and other students provide their replies to the teacher's quizzing questions, they do not only publicly reveal their semantic sprouts-connections, privately produced in response to teacher's mini-lecture (and prior discourse), but also they publicly make new semantic sprouts-connections. Also, their peers may continue producing their own semantic sprouts silently and privately in response to the teacher's questions, their peers' replies, the teacher's evaluations and elaborations on the peer's replies, and even their own discursive thinking. As to the nature of students' semantic sprouting - how much it is emergent in reaction to other people's (teachers' and peer students') discourse and demonstrations and how much it is based on deliberate actions on the part of the students - remains unclear and may differ from student to student.

Immediate semantic sprouting involves perceptual and semantic pattern-recognition, described by cognitive psychologist Daniel Kahneman as System\#1(2011). However, in contrast to Kahneman (and Vygotsky (1978)), I do not equate meaning-making with mediation. Kahneman seems to include nondeliberate and unmediated pattern-recognition in his System\#1 while including deliberate mediation in his 


\section{Pattern-recognition, intersubjectivity, and dialogic meaning-making in education}

Eugene Matusov

System\#2. Since he equates meaning-making with mediation, meaning-making is also a part of his System\#2. Although I agree that the meaning-making process involves mediation, it cannot be reduced to mediation (see my discussion of meaning-making below in this essay). I will discuss mediation later in the paper.

Deliberate semantic sprouting involves internal dialogue, reasoning, and meaning-making, Kahneman's System\#2 (but not only, see, Matusov, 2017). Deliberate semantic sprouting also includes immediate semantic sprouting - in a way, deliberate semantic sprouting is always a hybrid - but the reverse is not always true: immediate semantic sprouting can be pure, without any deliberate sprouting. Probably (my hypothesis), more autodidactic, active learners generate more deliberate semantic sprouting, while more peripheral and passive students experience more immediate semantic sprouting. Since conventional schooling heavily promotes the former (immediate semantic sprouting) and discourages the latter (deliberate semantic sprouting), I expect the overall prevalence of immediate over deliberate semantic sprouting in conventional school ${ }^{6}$.

Both pedagogical and psychological (indirect) evidence suggests that students' semantic sprouting does exist but is never guaranteed. The students' semantic sprouting exists even without the teacher's direct instruction (lecturing, demonstration, and so on), without the teacher's quizzing questions, without the teacher's providing evaluative feedback and elaborations. It may be true that the students' semantic sprouting is less likely to happen without the teacher's guidance, although, for many students (but not in all!) it is not impossible (e.g., Nicol \& Macfarlane-Dick, 2006). At the same time, the teacher's guidance does not guarantee students' sprouting, not in all students, not all the time, not a predictable type of sprouting. It is safe to assume that students' semantic sprouting is unpredictable in each and every case. However, the teacher's quizzing feedback provides cropping of wrong semantic sprouts to push the correct pattern-recognition and pattern-production. That is probably why classroom discourse involving the teacher's quizzing and feedback is so ubiquitous in modern conventional school.

\section{Teacher's approving and cropping of the students' semantic sprouts - scaffolding}

One of the pedagogical roles of a conventional teacher is to crop out the students' wrong semantic connections, approve and affirm the students' correct semantic connections, clarify some of their fuzzy right connections, and encourage building still missing right connections through the triadic classroom discourse: 1) Teacher's quizzing question, 2) Student's reply, 3) Teacher's evaluation (Lemke, 1990; Mehan, 1979; Sinclair \& Coulthard, 1975). To explicate the triadic discourse, the above exchange from Lemke's study will look like:

Teacher's quizzing question: This is a representation of the one $S \ldots$ orbital. S'pozed to be, of course, three dimensional... What two elements could be represented by such a diagram? ... Jennifer?

Student's response: Jennifer: Hydrogen and helium?

Teacher's evaluation and elaboration: Hydrogen and helium. Hydrogen would have one electron... somewhere in there... (p. 5)

The student (Jennifer) was sprouting a semantic question-answer connection, although she was not sure whether her semantic connection to the teacher's question was correct, from the teacher's point of view. The teacher approved the student's sprouting and elaborated on its justification (i.e., why the

\footnotetext{
${ }^{6}$ See my discussion below in this chapter.
} 


\section{Pattern-recognition, intersubjectivity, and dialogic meaning-making in education}

Eugene Matusov

pattern is correct) - mediated patterning, which may or may not mixed with genuine meaning-making for some particular students.

In another example, the teacher cropped a student's wrong sprout,

Teacher's quizzing question: If I have one electron in the $2 \mathrm{Px}$, one electron in the $2 \mathrm{Py}, \ldots$ two electrons in the $2 \mathrm{~S}$, two electrons in the $1 \mathrm{~S}$, what element is being represented by this configuration?... Ron?

Student's response: Ron: Boron?

Teacher's evaluation and mediation: That would be-That'd have uh . . . seven electrons.

So, you'd have to have one here, one here, one here, one here, one here . . . one here-Who said it? you?

The teacher tacitly rejected Ron's answer and mediated his rejection by explanation of why the chemical element boron did not fit the pattern presented on the diagram. Other students provided the correct spouting accepted by the teacher,

Student's response: Carbon.

Teacher's quizzing question [beginning]: What's-

Students' response: Carbon! Carbon!

Teacher's evaluation and elaboration: Carbon. Carbon. Here. Six electrons. And they can be anywhere within those-confining-orbitals. (pp. 15, 17)

The last exchange slightly deviated from the strict triadic discourse because the first student was making a response, unsanctioned by the teacher. Other students joined that student interrupting the teacher, who seemed to want to reiterate his previous question since Ron was wrong. The teacher sanctioned the student's response by evaluating their answers as correct ones. The teacher accepted unsanctioned (unnamed) student's response before.

In conventional schools, at times, the teacher's guidance of the students' discursive patternrecognition and pattern-production goes far beyond direct instruction (e.g., lecture, demonstration) and the triadic discourse, described above. Psychologist Jerome Bruner and his colleagues (Bruner, Wood, \& Ross, 1976) describe the guidance employed in conventional schools as "scaffolding." The goal of the scaffolding is for the teacher to actively lead the student to a curricular endpoint preset by the teacher in advance. In Lemke's case, the preset curricular endpoint apparently was the quantum model of the atom (and, specifically, the atomic orbits of electrons in the atom). Rogoff argues that scaffolding involves much more than the organization of discourse but also the teacher's management of the students' motivation, frustration, and challenges ${ }^{7}$, the teacher's presentation of the idealized pattern, and so on:

1. Recruiting the child's interest in the task as it is defined by the tutor.

2. Reducing the number of steps required to solve a problem by simplifying the task, so that the learner can manage components of the process and recognize when a fit with task requirements is achieved.

3. Maintaining the pursuit of the goal, through the motivation of the child and direction of the activity.

4. Marking critical features of discrepancies between what a child has produced and the ideal solution.

${ }^{7} \mathrm{Jim}$ Cresswell, who read a previous version of this manuscript, made a comment, that I agree with, "I would say it is the teacher's co-construction of these psychological predicates." 
5. Controlling frustration and risk in problem-solving.

6. Demonstrating an idealized version of the act to be performed (Rogoff, 1990, p. 94).

In Lemke's excerpt above, \#2, \#4, and \#6 of Rogoff's principles of scaffolding are evident as the teacher breaks the quantum model of the atom into chunks by his quizzing questions (and probably in his lecturing) and by revealing possible discrepancies between the ideal model and the students' replies via providing his evaluation of the students' responses. Also, the quantum model of the atom remains idealized as it is simplified in certain aspects (e.g., from quantum mechanics' point of view, strictly speaking, electrons do not have trajectories, and their "orbitals" represent probability distributions). The \#1, \#3, and \#5 principles are not present, but they may occur outside of the excerpt.

At the same time, Lemke's extract has two additional aspects that are not present in Rogoff's list: 7) triadic discourse involving teacher's quizzing question, student's response, and teacher's evaluation and elaboration; and 8) managing the discourse to make sure that the students' replies are always sanctioned by the teacher. The list of essential features of scaffolding is probably incomplete, and the issue of how essential each of the aspects is remains open for future investigation.

Now I want to turn to the issue of the contrast between conventional school pattern-recognition and pattern-production with: 1) pattern-recognition and production in everyday life, outside of conventional school, 2) learning guided by meaning-making rather than by pattern-recognition and production, and 3) the concept of genuine intrinsic education.

\section{Pattern-recognition/production in conventional school vs. everyday life}

I consider three dimensions that reveal the prevalent contrast between pattern-recognition and production in conventional school vs. in everyday life. These three dimensions involve: i) the relevance of the pattern-recognition/production for the students, ii) the ownership of the underlining values of the pattern, and iii) the realness of the pattern. I argue that in contrast to conventional school, the pattern-recognition and production process in everyday life is more often than not ontological rather than alienated (relevance), more authorial rather than technological (ownership), and more experiential rather than discursive (realness). I also consider progressive pedagogy as a pattern-recognition/production hybrid between conventional school and everyday life.

\section{Relevance: ontological vs. alienated}

Ontologica $\beta$ pattern-recognition and production involve a person's genuine interest in and/or genuine pragmatic need for this pattern. For example, a person who got a new remote control may search for new patterns of his or her actions with the new remote control leading to desired outcomes on the device associated with the remote control. In contrast to Lemke's case above, in this case of the new remote control, the person's motivation is rooted in the actor him/herself - his/her own ontology - and not in the teacher - in the teacher's pedagogical actions, motivating the student. In everyday pattern-recognition and production, the pattern is often desired and owned by the actor, while in school, the pattern is demanded and, thus, imposed by the authority. Alienated pattern-recognition and production involve unconditional pleasing of the authority (Matusov, 2011a). This pleasing - the student's desire to get the teacher to approve the pattern that emerges in or is actively designed by the student - guides the student's pattern-recognition and production. The pleasing is unconditional because the student is not legitimately involved in the

\footnotetext{
${ }^{8}$ Theological-philosophical term "ontology" is very polysemic. I used it within an existential philosophical tradition as "being-in-theworld."
} 
negotiation of what patterns he or she needs to recognize or produce. In conventional schools, a student does not have a legitimate voice in shaping the curriculum.

\section{Ownership: Authorial vs. technological}

Authorial pattern-recognition and pattern-production involve the actor's attention, consideration, and approval of the values, defining the recognized and/or produced patterns' success or failure. Bakhtin was similarly talking about putting one's own signature under one's deed (Bakhtin, 1993), taking responsibility for the value. In conventional school values, defining the patterns' success and failure are firmly controlled and possessed by the authority (i.e., the teachers, the test designers, graders, governmental agencies imposing the prescribed curriculum). In the case of learning an unfamiliar remote control, the actor him/herself decides what outcome is desirable (e.g., switching on the TV) and whether it is successful or not. In conventional school, pattern-recognition and production is technological because the teacher, often being disinterested him/herself, treats the student as a tool to produce the pattern that the teacher pedagogically desires to produce. Authorial pattern-recognition and production promotes authorial learning (Matusov, 2011a), which organizational psychologists Argyris and Shon (1978) called Learning 2. Since authorial pattern-recognition and production is guided by the actor's desires, owned by the actor, the actor has an opportunity to reflect on, revise, or even abandon the desire altogether. This is authorial learning or Learning 2.

In contrast, in technological learning, the desire guiding the pattern-recognition and production process is owned by the authority and is essentially non-negotiable for the student. This type of situation promotes Learning 1, or thermostat-like learning, or deficit model learning, focusing on the gap between the ideal desired pattern, controlled by the teacher, and the student's actual discursive or action-based performance as judged by the teacher (\#4 on Rogoff's list defining scaffolding).

In authorial learning, Learning 2 and Learning 1 co-occur, with Learning 2 guiding the process. Analyzing everyday problem solving, Lave (1988) concluded that everyday problem solving (Learning 1 ) is often based on problem redefining (Learning 2). For example, while shopping for the cheapest cereal, a shopper may redefine the criterion for successful shopping by also considering space for storing the large box of the cheapest cereal and not only its price. The shopping process often involves redefining what exactly the shopper wants through considering the choices of the products available in the store and negotiation of what patterns he or she needs to recognize or produce. In conventional schools, a student does not have a legitimate voice in shaping the curriculum.

\section{Realness: Experiential vs. discursive}

Finally, experiential pattern-recognition and production involves a person's holistic experience, rather than a discourse organized by the teacher that becomes the guiding force to form a desired perceptual or action-based pattern. Experiential pattern-recognition and production has "the reality check," while discursive pattern-recognition and pattern-production does not. In the latter case, "the resistance of material" - i.e., what makes student's perception and action right or wrong - is fully controlled by the school authority, which makes it arbitrary. In the extreme, the school can (and occasionally does) teach whatever nonsense - whatever untrue, irrelevant, and/or useless patterns to the students - it may wish (see Matusov, 2020, in press, Chapter 2, for an example of such teaching).

In contrast, in the former case, however arbitrary the actor's desires may be (e.g., making the TV fly by pressing certain buttons on the TV), the realizations of these desires - i.e., patterns for desired actions - are never arbitrary because they are firmly grounded in the reality of the world. I call conventional 


\section{Pattern-recognition, intersubjectivity, and dialogic meaning-making in education}

Eugene Matusov

schoolish knowledge "conventional" (Matusov, 2009) because its truth is based on the conventional authority for the students: something is true because the teacher or textbook or school exam or scientists or powerful societal traditional norm say so. Below, I will elaborate on this point when I consider intersubjectivity.

Saying all that, I want to nuance that, of course, in everyday life, there are many occasions for discursive pattern-recognition and pattern-production learning as well (e.g., learning a language). Also, experiential pattern-recognition and pattern-production can happen in conventional schools as well (e.g., lab science classes). Besides, discursive pattern-recognition and production may involve experiential aspects (e.g., semantic sprouting based on the student's past experiences), while experiential patternrecognition and production may involve discursive aspects (e.g., symbols on a remote control or the remote control manual or verbal guidance by other people). Finally, there can be school-like situations in everyday life and everyday-life-like situations in conventional schools (Matusov, 2009). Nevertheless, the overall contrast of the dominance of ontological, authorial, and experiential aspects of pattern-recognition and production in everyday life and the supremacy of alienated, technological, and discursive patternrecognition and production in conventional school remains more or less intact, in my view.

\section{Progressive pedagogical education hybrid}

Progressive pedagogical ${ }^{9}$ education, represented by famous American educational philosopher John Dewey, tries to address the problem of irrelevance, alienation, and non-authenticity of the students' school experiences by blending together conventional school and everyday pattern-recognition and production. Progressive pedagogy organizes instruction in the form of pragmatic experiential learning activities that funnel the students into the curricular endpoints preset by the society (i.e., "curricular standards") - i.e., a body of democratically elected local and national political representatives of the general public, educational scholars and philosophers, and disciplinary scholars (i.e., scientists) (Dewey, 1956). It promotes the ontological and experiential nature of pattern-recognition and production in the learning activities from everyday practices.

However, it preserves the control of the curriculum inherited in conventional schooling making the ownership of the patterns pseudo-authorial. It may feel like authorial at a local level of activities as students may have some freedom of defining their own values and set their own problems and goals in the learning activities, but eventually, the students' values, problems, and goals have to be funneled into the curricular endpoints preset by the society. However, besides this preset curricular core, the students can arrive at their own emergent curricular endpoints, which can be considered as personalized, authorial, extracurricular enrichment and may involve meaning-making outside of the pattern-recognition and production requirement.

\section{Intersubjectivity}

Intersubjectivity is a social pattern of behavior involving subjectivity. The intersubjective pattern can be based on different types of behavioral coordination among individuals (Matusov, 1996). This coordination may include sameness. For example, an infant follows the mother's outlook and, thus, sees what the mother sees (Murray \& Trevarthen, 1985). Alternatively, intersubjective coordination may involve a transactional relationship. For example, when a male wolf, losing a fighting, switches to a submissive role, becoming intentionally defenseless, while the other, winning, wolf assumes a dominant role (instead

\footnotetext{
9 The progressive pedagogical educational movement has to be distinguished from the progressive administrative educational movement. The latter focused on the organization of the institutional practices to make them more scientifically efficient and rational. The former focused on pedagogy to increase the relevance of pedagogical experiences for the students (Labaree, 2010).
} 


\section{Pattern-recognition, intersubjectivity, and dialogic meaning-making in education}

Eugene Matusov

of killing the defenseless rival) (Fogel, 1993). Or, it may involve a division of labor like in a modern enterprise.

Intersubjectivity can be immediate or mediated. The latter can involve shared beliefs or individual coordinated calculations. Thus, for example, dual bicycle sprint race often starts with the rivals staying or slowly moving, refusing to take the lead ${ }^{10}$. The intersubjective pattern involves a complex calculation. An immediate lead often results in losing because the leading bicyclist would use more energy overcoming the resistance of the air while the closely following bicyclist would save energy. However, this also depends on the distance between the bicyclists, their positions on the tracks, how far they are from the finish line, and so forth. In this case, the intersubjectivity is not only highly mediated by the bicyclists' calculations but also dynamic leading to diverse patterns.

Intersubjectivity does not only coordinate people but also creates a new socially constructed reality. For example, money is based on intersubjectivity.

Intersubjective entities depend on communication among many humans rather than on the beliefs and feelings of individual humans. Many of the most important agents in history are intersubjective. Money, for example, has no objective value. You cannot eat, drink or wear a dollar bill. Yet as long as billions of people believe in its value, you can use it to buy food, beverages and clothing. If the baker suddenly loses his faith in the dollar bill and refuses to give me a loaf of bread for this green piece of paper, it doesn't matter much. I can just go down a few blocks to the nearby supermarket. However, if the supermarket cashiers also refuse to accept this piece of paper, along with the hawkers in the market and the salespeople in the mall, then the dollar will lose its value. The green pieces of paper will go on existing, of course, but they will be worthless (Harari, 2017).

As Harari points out, intersubjectivity won't evaporate if a person stops believing in this socially constructed reality. The life of such an individual will become very difficult. By disbelieving in the intersubjective reality, the individual would disrupt it for other people, and the other people will push back the spoilsport ${ }^{11}$.

The social fabric of conventional education is entirely intersubjective. For example, in my graduate classes, sometimes I ask my students out of the blue, "What is two plus two?" Without exception, my students reply, "Four." This is even though my question was out of any immediate context of our class discussion. Also, my students know perfectly well that I know what two plus two is - they know that this is not an information-seeking question but rather a form of a teacher's quizzing. Interesting enough, when I asked some of them the same question outside of the class when we bumped into each other on a campus street or at a campus café, they never reply to me "four." Often, my students become confused, asking me to repeat the question, "What?" or "Why?!"12 They seem to want to know why I asked this strange, out context, question.

My little experiment reveals conventional school's intersubjectivity of socially constructed reality where a teacher can ask quizzing questions at will, abruptly, and out of context. The power of this

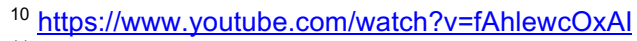

${ }^{11}$ Ana Marjanovic-Shane (2016) argues that genuine (dialogic meaning-making) education is based on spoilsports' deconstruction of the culturally given intersubjectivity. Students have to be placed in a position of such spoilsports.

12 You can watch a video fragment that shows reactions of adults after being asked schoolish, quizzing, questions outside of school context. People are confused, puzzled, disoriented, or laughing when are faced with schoolish questions in everyday life: https://youtu.be/uv1062T8Img
} 
intersubjectivity is very strong. Even if I told my students about my experiment in the classroom and then asked them what two plus two is, they revealed that it was very difficult for them to resist not to say "four." Obviously, they do not have this problem outside of the classroom. Intersubjectivity creates powerful "psychological affordances" (Gibson, 1979) - i.e. when a particular pattern of the environment or a particular situation forces an individual's actions even despite their will.

As I showed in the section above, teaching science (and other academic subjects) in conventional schools is mostly about the teacher's socialization of students in intersubjective socially constructed reality through a pattern-recognition and pattern-construction. Harari (2017) comments, "People constantly reinforce each other's [intersubjective] beliefs in a self-perpetuating loop. Each round of mutual confirmation tightens the web of meaning further until you have little choice but to believe what everyone else believes." As I will show below, individual or intersubjective, immediate or mediated, charged with psychological affordances or not, self-sufficient or embedded in webs of activities and relationships, behavioral and subjective patterns are not really meanings. They can become meanings only when they enter a sphere of dialogue.

\section{Dialogic meaning-making vs. pattern-recognition/production in education}

According to the Russian philosopher of dialogism Mikhail Bakhtin, meaning-making is dialogic. Dialogic meaning-making is defined as the relationship between a genuine, interested, information-seeking, question, and serious response to it (Bakhtin, 1986, 1999). This dialogic definition of meaning-making is dramatically different from a common monologic understanding of meaning-making. From a conventional monological point of view, meaning is located in a particular statement or rooted in a word, or in a gesture, or in a tool, or in a mediation (Mead, 1956; Vygotsky, 1978). From the Bakhtinian dialogic perspective, a statement/word/gesture/tool/mediation does not have any meaning until it is viewed as a reply to some question (in a broader sense as puzzlement, perplexity, tension, interrogation, inquiry, wonderment, and so on) ${ }^{13}$.

For example, often a mathematical statement like $2+2=4$ is viewed as meaningful because it tacitly replies to a question, "How much is 2 plus 2 ?" But in this case, the $2+2=4$ is really meaningful only if the question, "How much is 2 plus 2 ?" is a genuine, interested, information-seeking question, which is probably not the case for most or all of my readers. The meaning of my 2+2=4 statement for me is answering my own genuine question of what an example of dialogic meaning-making can be. However, my readers may imagine a different genuine, interested, information-seeking question behind my use of 2+2=4 example, and, in this case, they may have their own meaning, different from mine.

Also, my (and other people's) meaning-making may not need to be stable as we can come up with different questions while re-reading $2+2=4$ in "the same text" (thus, the text never remains the same). Although not necessarily language-based, meaning-making is always discursive and rooted in language. In a speech- and language-rich environment, human actions and silences find their discursive properties of raising and addressing questions to others. Although not necessarily always literally (physically) collective - as meaning-making can occur in one person during an internal dialogue or when reading others' written texts - meaning-making is an inherently social phenomenon. Any internal or imaginary dialogue within or by one person is always a purified and reduced genuine dialogue among real, living, people, who can genuinely (not imaginarily!) reply on their own behalf (Lobok, 2012, 2014; Matusov, 2009; Nikulin, 1998, 2006, 2010; Sidorkin, 1999). Opaqueness of the replying and addressing consciousness of the Other,

\footnotetext{
${ }^{13}$ Actually, Vygotsky also has an example of how a statement "the watch fell" may mean two entirely different things based on what questions it is answering (Vygotsky \& Kozulin, 1986). This is one of the times where he comes close to discussing dialogic meaningmaking, in my view.
}

Dialogic Pedagogy: An International Online Journal | https://dpj.pitt.edu DOI: $10.5195 /$ dpj.2020.314 | Vol. 8 (2020) 


\section{Pattern-recognition, intersubjectivity, and dialogic meaning-making in education}

Eugene Matusov

taking responsibility, interaddressivity, - are a few issues among many others that distinguish internal or imaginary dialogue from genuine dialogue with other people.

From an educational practice perspective, a student's meaning-making process starts with a genuine, interested, information-seeking question raised by the student, not by the teacher. At least, when a student cannot yet formulate this genuine question, they have to be pregnant with such a question, experiencing a certain puzzlement, uneasiness, curiosity, tension, and so on. Without a genuine question or at least puzzlement, uneasiness, curiosity, or tension, a student cannot be involved in a meaning-making process (Berlyand, 2009; Bibler, 2009) - and therefore cannot be involved in education. Provoking such types of questions in students is proto-teaching, preparation for teaching.

Socrates' dialogues, with the exception of his dialogue with a slave in Meno, started with students asking genuine questions (Matusov, 2009). That is why I argue that there is little visible evidence of the meaning-making process in Lemke's excerpt from a conventional science lesson above. Even when meaning-making may occur there, like in the student's (Jennifer) question, "Hydrogen and helium?", it is not clear how genuine, interested, and information-seeking, this question was for Jennifer. And even if so, her meaning-making was probably subordinated to her pattern-recognition to please the teacher. A fullblown meaning-making process, transcending the given, does not know preset curricular endpoints, educational standards, as its goal. The meaning-making process disrupts the given curricular standards and endpoints. It is wild and unpredictable (Lobok, 2001, 2012). It does not bow to any authority (cf. Bakhtin, 1991). It is bottomless (Bakhtin, 1986). It is unfinalizable in time and in principle as more and more questions can be raised, and different replies can be given (Nikulin, 2010).

Students' meaning-making is a social process that may require a teacher's, peers' and other people's help. Let's consider the following case of an emergent dialogic meaning-making process among elementary school fourth-grade students in a typing class:

A primary consideration in developing a community of inquiry is to give students ownership of the tasks and problems posed. Throughout the year, many mathematical investigations grew out of students' questions and observations from mathematics class, other subject areas, personal experiences, and children's literature. The following conversation prompted us to engage the students in a rich exploration in finding patterns in rational numbers. The students were working on a computer-assisted spelling program that reported individual results as a statement, such as "19 correct out of 20 or $95 \% . "$

Thom: I only missed one this time! [His report showed that he got 15 correct out of 16 , or $94 \%$.]

Will: Me, too! I got a 95. [He points to the screen and shows the other student. His report says that he got 19 correct out of 20 , or $95 \%$.]

Thom: Hey, why did you get a 95 when I got a 94 ? We both only missed one. That's not fair! Will: I think your computer is broken.

To begin our investigation, Thom and Will shared their conversation about their spelling scores. Some students agreed that the computer must have made an error; others thought that the computer could be right, but they were not sure why the percents were different. Although some students thought that the magnitude of the numbers might contribute to different percents, most of the students' conversation focused on the difference between the number of words spelled correctly and the total number of words. To prompt the students to explore the problem further, I posed the following question: "Suppose that you took a spelling test with only two words on it and you misspelled one of them. The computer reports that you got one word correct out of two. What percent of the 


\section{Pattern-recognition, intersubjectivity, and dialogic meaning-making in education}

Eugene Matusov

words did you get correct?" The students discussed this question for several minutes with their "math buddies." When asked to share, one pair of students responded that 1 out of 2 was 50 percent because only half the words were correct, and 50 percent means half. Other students chimed in and nodded agreement. We pointed out that 1 out of 2 means that you missed only one word, just as Thom got 15 out of 16 and Will got 19 out of 20 . We then asked why the percent scores were different.

Sheila: Ninety-five percent means that you almost got all the words correct. So, 15 but of 16 and 19 out of 20 should both be 95 percent, since you almost have all the words correct.

Teacher. Do you think that 1 out of 2 should also be 95 percent?

Sheila: One out of 2 is usually 50 percent, but it also could be 95 percent, since you almost have all the words correct.

John: No, 1 out of 2 is always 50 percent because 1 is half of 2 and half of something is 50 percent, just like 50 cents is always half of a dollar.

John, and most others, had a clear understanding that 1 out of 2 was always 50 percent; however, they were not able to reason why the three ratios resulted in different percents (Drier, 2000, p. 359).

Please note that here it was students Thom and Will and not their teacher who initiated the genuine question, inquiry, and puzzlement for themselves and the class (but not necessary for the teacher who might feel that she knew the answer). However, in a dialogic meaning-making pedagogy, a teacher can provoke students' questions, inquiries, and puzzlements. It was OK for the teacher to recognize this math inquiry raised by the students as a legitimate learning problem during a language-arts lesson. Meaningmaking does not know academic subject boundaries or, actually, any boundaries - Bakhtin (1986) called this feature of the dialogic meaning-making process "heterodiscoursia," ${ }^{4}$ literally "a diversity of ways of speaking, " "a diversity of discourses." Another important aspect of the full-blown dialogic meaning-making process is that it is not and cannot be validated by an authority (e.g., the teacher) but only by the discourse itself. Bakhtin (1991) called it "internally persuasive discourse," contrast to "authoritative discourse" (e.g., of a conventional school) where validations of contributions come exclusively from the authority. However, my colleague and I argue that in this discourse, the internal of its persuasion and validation come from the discourse itself - it is internal to the discourse itself - and not to the individual (i.e., internal to the individual mind) (Matusov \& von Duyke, 2010). In an internally persuasive discourse, each and every participant remains the only legitimate judge for themselves of how much each meaning-making contribution is valid or contested. Of course, this authorial judgment is never final and remains challenged by authorial judgments by other people now or in the future.

The third important feature of the internally persuasive meaning-making discourse is that the outcomes of the discourse, viewed by the participants as always provisional, are unpredictable and can lead in many directions. In the given case, the computer (and, apparently, the teacher) accessed spelling accuracy by the proportion of correct words to total words. This mathematical model was based on many questionable assumptions apparently rejected by Thom, Will, and Sheila. Thus, this mathematical model implied that all mistakes were the same. However, imagine that a student made a spelling mistake and learned from it, avoiding a similar mistake in the future. In this case, arguably, a student's spelling accuracy becomes $100 \%$, since a student becomes perfect at spelling. In another case, that of a spelling bee competition, making one mistake means that the contestant has lost the competition - it does not matter when it occurred and with how many words. It is either $100 \%$ or $0 \%$.

\footnotetext{
${ }^{14}$ Unfortunately, in the English translation, a wrong term, "intertextuality", was used for the Russian term "raznorech'e" ("разноречье") (Todorov, 1984). I introduced a better translation "heterodiscoursia" in a parallel to another Bakhtinian term "heteroglossia" ("разноголосье") that was well-translated in English (Matusov, 2011b).
} 


\section{Pattern-recognition, intersubjectivity, and dialogic meaning-making in education}

Eugene Matusov

The computer's (and the teacher's) math model implies, among other things, the spelling accuracy continuity - i.e., if a student makes one mistake out of 2 words, for example, he or she will continue making mistakes with the same frequency of $50 \%$. Of course, this is very questionable. A student who made one mistake out of 20 (like Will) might continue not making spelling mistakes for the next 1,000 words (or not) or may start learning from his mistakes. From this perspective, students who made just one mistake were equally accurate regardless of how many words they wrote. This is what Thom, Will, and Sheila seemed to imply to me. Unfortunately, the teacher did not investigate their assumptions that require different math models from the one that both the computer and the teacher used. John's position was unclear to me and also seemed not to have been explored by the teacher. This leads me to conclude that this dialogic meaning-making process was rather limited and a bit unguided.

As the case suggests, dialogic meaning-making may not guarantee any productive outcome, however provisional it may be. It may flexibly dissolve any particular thematic focus (Nikulin, 2006, 2010). In this particular case, we do not know how much the teacher respected this principle of the full-blown dialogic meaning-making process - she might or might not funnel the discursive process to her preset curricular point. If she did, she would be a progressive educator, subordinating and exploiting the students' dialogic meaning-making for the pattern-recognition process (see above).

Although patterns of perception, patterns of action, patterns of communication, patterns of relation, patterns of power, patterns of thinking, and so on can become a subject of dialogic meaning-making, there is an essential difference between patterns and dialogic meaning as such in, at least, two important aspects. First, in the dialogic meaning-making process, people are not only genuinely, ontologically, interested in it - resolving some question, tension, puzzlement, inquiry, and so on - but also in other people: 1) in what other people may think and how they feel about it; however these people define this it, and 2) in other people as such - in what they are doing, feeling, relating, and thinking about; in the relationship with these people; in the potential that these people may realize and offer; and so on (Nikulin, 2006, 2010). I called this aspect of dialogic meaning-making "interaddressivity" - i.e., genuine and deep interest in the people's dialogic interlocutors (Matusov, 2011b).

The interaddressive interest in it vs. in people, i.e., in one's dialogic partners, may vary and can create an important tension in a dialogic meaning-making process. In contrast, pattern-recognition is always concerned with it - would it be things, processes, behaviors, or even people. Pattern-recognition does not address or reply - meaning-making does.

Second, in pattern-recognition, one tries to grasp the complete form of things, processes, behaviors, actions, perceptions, and events - i.e., finalize them. As with creating any form, one finalizes and conceives of the pattern as finalizable, even when this form of the pattern is probabilistic (e.g., a probabilistic pattern of winning in a lottery) - a pattern of probability. Pattern-recognition is exhaustible and has its bottom.

In contrast, meaning-making is relational (i.e., the relation between the genuine question and serious answer), bottomless, inexhaustible, unfinalized, and unfinalizable in principle (Bakhtin, 1986; Nikulin, 2006, 2010). Pattern can become meaningful only when it is dialogized. In sum, pattern-recognition per se is essentially monologic, while meaning-making is essentially dialogic. 


\section{Conclusion: Pattern-recognition/production and dialogic meaning-making vs. education}

Finally, I want to address the question of how the monologic pattern-recognition/production pedagogies and the dialogic meaning-making pedagogies are situated within the practice of education. Both pattern-recognition/production and meaning-making processes are often present in both monologic and dialogic pedagogies. However, these processes play different roles in each pedagogy. In the monologic, conventional and innovative, dialogic meaning-making, if it occurs at all, is subordinated to the emergence of the "correct" pattern - correct from either the authority's point of view or/and from the pragmatic point of view. In the dialogic pedagogies, pattern-recognition/production is subordinated to this meaning-making. I think that all pedagogies are a pattern-meaning hybrid, which may have both forces at play. Prioritization of one of these two aspects defines the nature of the pedagogy.

I argue that the monologic pattern-recognition/production pedagogies are mainly concerned with and primarily focused on the reproduction of and socialization in existing, ready-made, culture, and specific cultural practices. The alienated pattern-recognition of conventional school approaches this task by chunking the ready-made culture into self-contained basic skills (e.g., reading, writing, calculating), basic prescribed knowledge, and basic dispositions. The students' authorial agency is postponed until their education is "completed" (Matusov, von Duyke, \& Kayumova, 2016). Some educators call this type of education - "training" (e.g., Dearden, 1984). In contrast, the innovative pattern-recognition of progressive school approaches this task by engaging the students in ontologically attractive learning activities that are a funnel to carefully preselected holistic ready-made cultural practices. My colleague Ana MarjanovicShane and I called this type of education - "closed participatory socialization in a targeted cultural practice" (Matusov \& Marjanovic-Shane, 2012). We call it "socialization" because, in contrast to training, it views the ready-made practice holistically, involving the participants' social relations and identities. We call this socialization "closed" because it does not see students' potential or actual contributions to transform, modify, or transcend this ready-made cultural practice as legitimate.

The dialogic meaning-making pedagogies are interested in transcending existing ready-made practices, relations, and communities of practices and in creating new ones through creative dialogic meaning-making by raising questions, concerns, issues, inquiries, curiosities, problems, challenges, controversies, and so on (Kovbasyuk \& Blessinger, 2013). The dialogic meaning-making pedagogies are authorial as they expect and legitimize students' authorship in making culture.

Ana Marjanovic-Shane and I (2012) distinguish at least two major dialogic meaning-making pedagogies. We called one "open participatory socialization" because it mainly focuses on the successful and creative socialization of the students in existing and innovative practices, while this socialization remains open for the student's authorial inputs and contributions. In open participatory socialization, students can legitimately transcend the practice, in which they socialize. This education involves culturemaking - construction of a new practice - rather than culture reproduction. It prioritizes creative authorship in the students.

We call the other dialogic meaning-making pedagogy "critical dialogue" because it mainly focuses on critical examination of the existing and new self, culture, world, practices, and society, while it views open participatory socialization as its by-product. It promotes critical authorship in the students. We presented all four pedagogies in the following table (I slightly updated this table by adding the new, third, column on types of pedagogy and by adding references in the second column): 
Table 1: Diverse approaches to education (based on Matusov \& Marjanovic-Shane, 2012, p. 165)

\begin{tabular}{|l|l|l|l|l|}
\hline $\begin{array}{l}\text { Approaches to } \\
\text { education }\end{array}$ & Example & Types of pedagogy & Curriculum & Instruction/guidance \\
\hline $\begin{array}{l}\text { Alienated } \\
\text { Learning }\end{array}$ & $\begin{array}{l}\text { Often conventional } \\
\text { schooling }\end{array}$ & $\begin{array}{l}\text { Pattern- } \\
\text { recognition/ } \\
\text { production } \\
\text { (alienated, } \\
\text { technological, } \\
\text { discursive) }\end{array}$ & $\begin{array}{l}\text { Poiesis: } \\
\text { reproduction } \\
\text { of ready- } \\
\text { made culture }\end{array}$ & Poiesis \\
\hline $\begin{array}{l}\text { Closed } \\
\text { Sarticipatory }\end{array}$ & $\begin{array}{l}\text { "Imitative } \\
\text { participation", } \\
\text { progressive } \\
\text { education, } \\
\text { appropriation of the } \\
\text { ready-made culture } \\
\text { (Van Oers, 2012; } \\
\text { Vygotsky, 1978) }\end{array}$ & $\begin{array}{l}\text { Pattern- } \\
\text { recognition/ } \\
\text { production } \\
\text { (ontological, } \\
\text { pseudo authorial, } \\
\text { experiential) }\end{array}$ & $\begin{array}{l}\text { Poiesis: } \\
\text { reproduction } \\
\text { of ready- } \\
\text { made culture }\end{array}$ & Praxis \\
\hline $\begin{array}{l}\text { Open } \\
\text { Participatory } \\
\text { Socialization }\end{array}$ & $\begin{array}{l}\text { "Community of } \\
\text { practice", } \\
\text { "legitimate } \\
\text { peripheral } \\
\text { participation" (Lave } \\
\text { \& Wenger, 1991; } \\
\text { Wenger, 1998) }\end{array}$ & $\begin{array}{l}\text { Dialogic meaning- } \\
\text { making (creative) }\end{array}$ & $\begin{array}{l}\text { Praxis: } \\
\text { production } \\
\text { of culture }\end{array}$ & Praxis \\
\hline $\begin{array}{l}\text { "Dialogic Education } \\
\text { For Authorial } \\
\text { Agency" (Matusov, } \\
\text { Smith, Soslau, } \\
\text { Marjanovic-Shane, \& } \\
\text { von Duyke, 2016) }\end{array}$ & $\begin{array}{l}\text { Dialogic meaning- } \\
\text { making (critical) }\end{array}$ & $\begin{array}{l}\text { Praxis of } \\
\text { praxis: } \\
\text { critical } \\
\text { stance on } \\
\text { culture }\end{array}$ & Praxis \\
\hline
\end{tabular}

As I stated above, we used Aristotelian notions of "poiesis" and "praxis" to characterize curriculum and instruction in these four types of pedagogy (Aristotle, 2000; Carr, 2006). Poiesis refers to an activity, in which its goal and the definition of quality preset (standards) and preexist the activity itself. In contrast, praxis refers to an activity, in which its goal and the definition of quality emerges in the activity itself. Thus, alienated pattern-recognition/production of conventional school involves poiesis of both standardized curriculum and standardized instruction as both of them are preset in advance. "Standardized social and cultural behavior patterns limit creative and authentic communication between individuals and groups" (Dumazedier, 1974, p. 72).

When instrumentalism, servility, efficiency, survival, and necessities take over and are prioritized, they become enemies of true democracy, true dialogue, true education, and true self-realization. In a pattern-recognition/production pedagogy of closed participatory socialization in progressive schooling, the curriculum remains poiesis while instruction becomes authorial praxis. In a dialogic meaning-making pedagogy of open participatory socialization, both curriculum and instruction become praxis. Finally, in a dialogic meaning-making pedagogy of critical dialogue, instruction remains praxis while curriculum 


\section{Pattern-recognition, intersubjectivity, and dialogic meaning-making in education}

Eugene Matusov

becomes "praxis of praxis" - i.e., critical examination of life (cf. Socrates' motto, "The unexamined life is not worth living," Plato \& Riddell, 1973).

In my upcoming book (Matusov, 2020, in press), I argue that only the latter should be the legitimate overall goal of genuine education. One may argue that by this statement, defining the goal of genuine education, I made education practice close and finalized - i.e., poiesis-like, in contradiction to my previous claims that genuine education should be praxis-like, in which its goal has to emerge in the activity itself. However, in my view, my definition of genuine education is self-deconstructive because it involves a critical examination of education itself as an aspect of one's life (and critical exanimation of the criticality itself - its limitations).

But the question still remains: why is the alienated pattern-recognition/production pedagogy of conventional schooling so prevalent in the past and present of our society ${ }^{15}$ ? Standards-based schooling teaches students conventional knowledge that arguably constitutes "cultural capital" (Hirsch, 1996), creates hegemonic consensuses in the society (Gee, 1996), and prepares workers for their future workplaces that require these standards and mental templates (Labaree, 1997). Arguably, conventional knowledge can help people achieve success in practices without it being dialogically persuasive. One does not need to know all reasons for conventional knowledge being correct (leave it to the experts!) to enjoy its fruits - at the end of the day, what matters is to act correctly in some objective way, and this will carry success in practice. Although this attitude can be highly pragmatic and useful, it is anti-educational. I do not say that educational concerns should always be prioritized over pragmatic ones, but I argue that it is important to distinguish pragmatic concerns from educational and not confuse pragmatic utility of training with genuine education. The mainstream education is based on the utilitarian claim that standards are the basis and the cornerstone of our modern society.

\section{References}

Argyris, C., \& Schön, D. A. (1978). Organizational learning: A theory of action perspective. Reading, MA: AddisonWesley Pub. Co.

Aristotle. (2000). Nicomachean ethics (R. Crisp, Trans.). Cambridge, UK: Cambridge University Press.

Bakhtin, M. M. (1986). Speech genres and other late essays. Austin, TX: University of Texas Press.

Bakhtin, M. M. (1991). The dialogic imagination: Four essays by M. M. Bakhtin (C. Emerson \& M. Holquist, Trans.). Austin, TX: University of Texas Press.

Bakhtin, M. M. (1993). Toward a philosophy of the act (V. Liapunov, Trans. 1st ed.). Austin: University of Texas Press.

Bakhtin, M. M. (1999). Problems of Dostoevsky's poetics. Minneapolis: University of Minnesota Press.

Berlyand, I. E. (2009). A few words about Bibler's dialogics: The School of the Dialogue of Cultures conception and curriculum. Journal of Russian \& East European Psychology, 47(1), 20-33. doi:10.2753/RPO10610405470101

Bibler, V. S. (2009). The foundations of the School of the Dialogue of Cultures program. Journal of Russian \& East European Psychology, 47(1), 34-60. doi:10.2753/RP01061-0405470102

Bishop, C. M. (2006). Pattern recognition and machine learning. New York: Springer.

Bruner, J., Wood, D., \& Ross, G. (1976). The role of tutoring in problem solving. Journal of Child Psychology and Psychiatry, 17, 89-100.

Carr, W. (2006). Philosophy, methodology and action research. Journal of Philosophy of Education, 40(4), 421-435. doi:10.1111/j.1467-9752.2006.00517.x

Dearden, R. (1984). Education and training. Westminster Studies in Education, 7(1), 57-66.

Dewey, J. (1956). The child and the curriculum and the school and society (Combined ed.). Chicago: University of Chicago Press.

${ }^{15} \mathrm{I}$ explore this question in details in my upcoming book (Matusov, 2020, in press).

Dialogic Pedagogy: An International Online Journal | https://dpj.pitt.edu

DOI: $10.5195 /$ dpj.2020.314 | Vol. 8 (2020) 


\section{Pattern-recognition, intersubjectivity, and dialogic meaning-making in education}

Eugene Matusov

Drier, H. S. (2000). Investigating mathematics as a community of learners. Teaching Children Mathematics, 6(6), 358363.

Du Bois, W. E. B. (1961). The souls of black folks. New York: Dodd, Mead \& Company.

Dumazedier, J. (1974). Sociology of leisure. New York: Elsevier Scientific Publ. Co.

Fogel, A. (1993). Developing through relationships: Origins of communication, self, and culture. Chicago: University of Chicago Press.

Forman, E. A., Minick, N., \& Stone, C. A. (Eds.). (1993). Contexts for learning: Sociocultural dynamics in children's development. New York: Oxford University Press.

Gee, J. P. (1996). Social linguistics and literacies: Ideology in discourses (2nd ed.). London: Taylor \& Francis.

Gibson, J. J. (1979). The ecological approach to visual perception. Boston: Houghton Mifflin.

Harari, Y. N. (2017). Homo Deus: A brief history of tomorrow (First U.S. edition. ed.). New York: HarperCollins Publishers.

Hirsch, E. D. (1996). The schools we need and why we don't have them (1st ed.). New York: Doubleday.

Kahneman, D. (2011). Thinking, fast and slow (1st ed.). New York: Farrar, Straus and Giroux.

Koffka, K. (1935). Principles of gestalt psychology. New York: Harcourt, Brace and Company.

Köhler, W. (1929). Gestalt psychology. New York,: H. Liveright.

Kovbasyuk, O., \& Blessinger, P. (2013). Meaning-centered education: International perspectives and explorations in higher education. New York: Routledge, Taylor \& Francis Group.

Labaree, D. F. (1997). How to succeed in school without really learning: The credentials race in American education. New Haven, CT: Yale University Press.

Labaree, D. F. (2010). Someone has to fail: The zero-sum game of public schooling. Cambridge, MA: Harvard University Press.

Lave, J. (1988). Cognition in practice: Mind, mathematics, and culture in everyday life. Cambridge, UK: Cambridge University Press.

Lave, J. (1992). Word problems: A microcosm of theories of learning. In P. Light \& G. Butterworth (Eds.), Context and cognition: Ways of learning and knowing. (pp. 74-92). Hillsdale, NJ: Lawrence Erlbaum Associates, Inc.

Lave, J., \& Wenger, E. (1991). Situated learning: Legitimate peripheral participation. Cambridge, UK: Cambridge University Press.

Lemke, J. L. (1990). Talking science: Language, learning, and values. Norwood, NJ: Ablex Pub. Corp.

Lobok, A. M. (2001). The probabilistic world: The chronicles of the philosophical-pedagogical reflections of an educational experiment. Yekaterinburg, Russia: Association of Small Businesses.

Lobok, A. M. (2012). My educational odyssey to dialogic agency-based probabilistic pedagogy. Journal of Russian and Eastern European Psychology, 50(6), 5-8.

Lobok, A. M. (2014). Education/obrazovanie as an experience of an encounter. Dialogic Pedagogy: An International Online Journal, 2, S1-S5. http://dpi.pitt.edu/ojs/index.php/dpj1/article/view/84 doi:10.5195/dpj.2014.84

Luria, A. R. (1976). Cognitive development, its cultural and social foundations. Cambridge, MA: Harvard University Press.

Marjanovic-Shane, A. (2016). "Spoilsport" in drama education vs. dialogic pedagogy. Dialogic Pedagogy: An International Online Journal, 4, A45-A80. http://dpj.pitt.edu/ojs/index.php/dpj1/article/view/151/113 doi:10.5195/dpj.2016.151

Matusov, E. (1996). Intersubjectivity without agreement. Mind, Culture, and Activity, 3(1), 25-45. doi:http://dx.doi.org/10.1207/s15327884mca0301 4

Matusov, E. (2009). Journey into dialogic pedagogy. Hauppauge, NY: Nova Science Publishers.

Matusov, E. (2011a). Authorial teaching and learning. In E. J. White \& M. Peters (Eds.), Bakhtinian pedagogy: Opportunities and challenges for research, policy and practice in education across the globe (pp. 21-46). New York: Peter Lang Publishers.

Matusov, E. (2011b). Irreconcilable differences in Vygotsky's and Bakhtin's approaches to the social and the individual: An educational perspective. Culture \& Psychology, 17(1), 99-119. doi:10.1177/1354067X10388840

Matusov, E. (2017). Severe limitations of the poietic individual mind. Review of the book. Review of the book [Kahneman, D. (2011). Thinking, fast and slow. New York: Farrar, Straus and Giroux.] Dialogic Pedagogy: An International Online Journal, 5, R1-R8. doi:10.5195/dpj.2017.178

Dialogic Pedagogy: An International Online Journal | https://dpj.pitt.edu

DOI: 10.5195/dpj.2020.314 | Vol. 8 (2020) 


\section{Pattern-recognition, intersubjectivity, and dialogic meaning-making in education}

Eugene Matusov

Matusov, E. (2020, in press). Envisioning education in a post-work leisure-based society: A dialogic perspective. New York: Palgrave.

Matusov, E., \& Marjanovic-Shane, A. (2012). Diverse approaches to education: Alienated learning, closed and open participatory socialization, and critical dialogue. Human Development, 55(3), 159-166. doi:10.1159/000339594

Matusov, E., Smith, M. P., Soslau, E., Marjanovic-Shane, A., \& von Duyke, K. (2016). Dialogic education from and for authorial agency. Dialogic Pedagogy: An International Online Journal, 4, A162-A197. http://dpi.pitt.edu/ojs/index.php/dpj1/article/view/172/130 doi:10.5195/dpj.2016.172

Matusov, E., \& von Duyke, K. (2010). Bakhtin's notion of the Internally Persuasive Discourse in education: Internal to what? (A case of discussion of issues of foul language in teacher education). In K. Junefelt \& P. Nordin (Eds.), Proceedings from the Second International Interdisciplinary Conference on perspectives and limits of dialogism in Mikhail Bakhtin Stockholm University, Sweden June 3-5, 2009 (pp. 174-199). Stockholm: Stockholm University.

Matusov, E., von Duyke, K., \& Kayumova, S. (2016). Mapping concepts of agency in educational contexts. Integrative Psychological and Behavioral Science, 50(3), 420-446. doi:10.1007/s12124-015-9334-2

Mead, G. H. (1956). On social psychology. Chicago: University of Chicago Press.

Mehan, H. (1979). Learning lessons: Social organization in the classroom. Cambridge, MA: Harvard University Press.

Milgram, S. (1974). Obedience to authority: An experimental view (1st ed.). New York,: Harper \& Row.

Murray, L., \& Trevarthen, C. (1985). Emotional regulation of interactions between two-month-olds and their mothers. In T. Field \& N. A. Fox (Eds.), Social perception in infants (pp. 177-197). Norwood, NJ: Ablex Pub. Corp.

Nicol, D. J., \& Macfarlane-Dick, D. (2006). Formative assessment and self-regulated learning: A model and seven principles of good feedback practice. Studies in higher education, 31(2), 199-218.

Nikulin, D. V. (1998). Mikhail Bakhtin: A theory of dialogue. Constellations, 5(3), 381-402.

Nikulin, D. V. (2006). On dialogue. Lanham, MD: Lexington Books.

Nikulin, D. V. (2010). Dialectic and dialogue. Stanford, CA: Stanford University Press.

Plato, \& Riddell, J. (1973). The Apology of Plato, with a revised text and English notes, and a digest of Platonic idioms. New York: Arno Press.

Rogoff, B. (1990). Apprenticeship in thinking: Cognitive development in social context. New York: Oxford University Press.

Scribner, S. (1977). Modes of thinking and ways of speaking: Culture and logic reconsidered. In P. N. Johnson-Laird \& P. C. Wason (Eds.), Thinking (pp. 483-500). Cambridge, UK: Cambridge University Press.

Scribner, S., \& Cole, M. (1981). The psychology of literacy. Cambridge, MA: Harvard University Press.

Sidorkin, A. M. (1999). Beyond discourse: Education, the self, and dialogue. Albany, NY: State University of New York Press.

Sinclair, J. M., \& Coulthard, M. (1975). Towards an analysis of discourse: The English used by teachers and pupils. London: Oxford University Press.

Sutton, R. S., \& Barto, A. G. (1998). Reinforcement learning: An introduction. Cambridge, MA: MIT Press.

Todorov, T. (1984). Mikhail Bakhtin: The dialogical principle. Minneapolis: University of Minnesota Press.

Van Oers, B. (2012). Meaningful cultural learning by imitative participation: The case of abstract thinking in primary school. Human Development, 55(3), 136-158.

Vygotsky, L. S. (1978). Mind in society: The development of higher psychological processes. Cambridge, MA: Harvard University Press.

Vygotsky, L. S., \& Kozulin, A. (1986). Thought and language (Translation newly rev. and edited / ed.). Cambridge, MA: MIT Press.

Vygotsky, L. S., \& Luria, A. R. (1993). Studies on the history of behavior: Ape, primitive, and child. Hillsdale, NJ: Lawrence Erlbaum Associates.

Wenger, E. (1998). Communities of practice: Learning, meaning, and identity. Cambridge, UK: Cambridge University Press.

Dialogic Pedagogy: An International Online Journal | https://dpj.pitt.edu

DOI: $10.5195 /$ dpj.2020.314 | Vol. 8 (2020) 


\section{(cc) EY}

New articles in this journal are licensed under a Creative Commons Attribution 4.0 United States License.

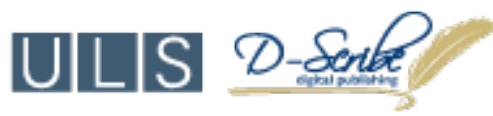

This journal is published by the University Library System, University of Pittsburgh as part of its D-Scribe Digital Publishing Program and is cosponsored by the University of Pittsburgh Press. 